\title{
The structure of symptoms of posttraumatic stress disorder according to DSM-5 and assessed by PDS-5 - preliminary results
}

\author{
Bogdan Zawadzki ${ }^{1 \cdot A, C, D, E, F, G}$, Agnieszka Popiel ${ }^{2 \cdot A, D, E, F, G}$, Edna B. Foa ${ }^{3 \cdot D, E, F}$, \\ Barbara Jakubowska ${ }^{4 \cdot A, B, E}$, Maria Cyniak-Cieciura ${ }^{4 \cdot D, E, F}$, Ewa Pragłowska ${ }^{5 \cdot A, B, G}$ \\ 1: The Robert Zajonc Institute for Social of Studies, University of Warsaw, Warsaw, Poland \\ 2: Department of Psychology, Department of Neurorehabilitation, Warsaw University of Social Sciences \\ and Humanities, Warsaw, Poland \\ 3: Center for the Treatment and Study of Anxiety, University of Pennsylvania, USA \\ 4: Department of Psychology of Individual Differences, Faculty of Psychology, University of Warsaw, Warsaw, Poland \\ 5: Interdisciplinary Center for Behavior Genetic Research, University of Warsaw, Warsaw, Poland
}

\section{BACKGROUND}

The structure of posttraumatic stress disorder (PTSD) symptoms has been studied and discussed since the introduction of PTSD as a diagnostic entity in the DSM-III (Diagnostic and Statistical Manual of Mental Disorders III) in 1980. Many studies supported a four-factor or a five-factor models, both inconsistent with DSM-IV. It is unclear whether current DSM-5 criteria appropriately reflect the empirical structure of PTSD symptoms.

\section{PARTICIPANTS AND PROCEDURE}

In this study the structure of PTSD symptoms was examined by confirmatory factor analysis conducted on the data obtained from 388 individuals ( 150 males and $239 \mathrm{fe}-$ males aged 18-83) who experienced a traumatic event and completed the PDS-5 (Posttraumatic Diagnostic Scale-5), a self-report scale according to the DSM- 5 criteria.

\section{RESULTS}

Fitting of different models based on DSM-IV, DSM-5 and other the most common four- and five-factor conceptualizations of PTSD symptoms structure was examined. The data analyses demonstrated the best fit of the six-factor model based on the conceptualization of Elhai et al. (2011) with the additional factor of negative cognitions and mood.

\section{CONCLUSIONS}

The DSM-5 diagnostic criteria do not reflect the empirical PTSD symptom structure. The data suggest also that it is reasonable to separate the core PTSD symptoms from broad PTSD symptomatology.

KEY WORDS

PTSD; DSM-5; PDS-5; structure of symptoms

CORRESPONDING AUthor - Prof. Bogdan Zawadzki, The Robert Zajonc Institute for Social of Studies, University of Warsaw, 5/7 Stawki Str., 00-183 Warsaw, Poland, e-mail: bogdan@psych.uw.edu.pl authors' CONTRibution - A: Study design - B: Data collection - C: Statistical analysis - D: Data interpretation .

E: Manuscript preparation $\cdot F$ : Literature search $\cdot$ G: Funds collection

to Cite this ARTICle - Zawadzki, B., Popiel, A., Foa, E. B., Jakubowska, B., Cyniak-Cieciura, M., \& Pragłowska, E.

(2015). The structure of symptoms of posttraumatic stress disorder according to DSM-5 and assessed by PDS-5 -

preliminary results. Current Issues in Personality Psychology, 3(1), 1-11.

RECEIVED 18.12.2014 · REVIEWED 07.01.2015 · ACCEPTED 10.02.2015 · PUBLISHED 06.03.2015 


\section{BACKGROUND}

Posttraumatic stress disorder (PTSD) was included in the DSM-III (Diagnostic and Statistical Manual of Mental Disorders III) classification in 1980 (American Psychiatric Association, 1980), and this was the starting point for many discussions and research on the structure of PTSD symptoms. Posttraumatic stress disorder is a chronic, frequently disabling disorder resulting from a traumatic experience. The lifetime prevalence of PTSD is approximately $6.80 \%$ in people who have been exposed to actual or threatened death, or serious injury (due to war, violence, natural or man-made disasters and accidents: American Psychiatric Association, 1980, 2000, 2013; Kessler, Berglund, Demler, Jin, \& Walters, 2005). It can be conceptualized as an impediment to natural recovery after the trauma, and is characterized by distress and problems in functioning of an individual due to persistent symptoms of: re-experiencing the event (intrusive thoughts, nightmares, flashbacks), avoidance of trauma reminders (thoughts, places, activities), autonomous arousal (vigilance, irritability, elevated startle response, sleep problems). Additional symptoms are reckless behaviors and negative alterations in cognitions (negative view of self, the world and others, self blame) and mood (feeling anxious or guilty), and inability to recall an important aspect of the event (for the full list of symptoms according to DSM-IV and DSM-5 see Table 1).

Clinical diagnosis requires confirmation of significant distress or impairment in functioning as well as meeting a number of criteria (symptoms with onset or exacerbation after the traumatic event) for more than 1 month. The debate about the empirical structure of nosological DSM diagnoses is far from concluded, and this paper presents a contribution to the discussion (Friedman \& Karam, 2009).

While early research on the symptom structure of PTSD utilized mostly exploratory factor analysis, currently practice utilizes confirmatory factor analysis (CFA). Research results (Elklit \& Shevlin, 2007; Krause, Kaltman, Goodman, \& Dutton, 2007) suggest that neither the three-factor model proposed by DSM-IV (American Psychiatric Association, 2000) - intrusion (B1-B5 symptoms), avoidance (C1-C7 symptoms) and hyperarousal (D1-D5) - nor one- and two-factor models, supported by the meta-analysis of 40 studies conducted by Yufik and Simms (2010), sufficiently describes the empirical structure. These findings led Elhai \& Palmieri (2011) to the conclusion that incorporating these models in further confirmatory factor analysis is no longer reasonable and justified. Our previous research on motor vehicle accident survivors, where PTSD symptoms were assessed by the Structural Clinical Interview for DSM-IV disorders (SCID-I) - PTSD module, showed that the latent structure of PTSD symptoms is more complicated and advanced than what DSM-IV proposes. However, it yielded inconclusive results, i.e., it did not clearly support the fivefactor over the four-factor model (Zawadzki, Popiel, Cyniak-Cieciura, Jakubowska, \& Pragłowska, 2015).

Another conclusion from the Yufik and Simms meta-analysis (2010) was that the two different four- factor models were supported: in most cases the one by King, Leskin, King, and Weathers (1998) and the second one by Simms, Watson, and Doebbelling (2002), with a small advantage of the Simms et al. (2002) model. King et al. (1998) found in their research that the module best describing PTSD symptoms consists of four factors: intrusion (B1-B5), hyperarousal (D1-D5) and category C separated into avoidance (C1-C2) and numbing (C3-C7), which was then called the 'Emotional Numbing' model and was supported by different research, inter alia Asmundson et al. (2000), Elhai, Palmieri, Biehn, Frueh, and Magruder (2010), McWilliams, Cox, and Asmundson (2005), Palmieri, Weathers, Difede, and King (2007). The competitive Simms et al. (2002) model postulated separation of categories $\mathrm{C}$ and $\mathrm{D}$ in a different way - into avoidance (C1-C2), hyperarousal (D4-D5) and dysphoria (C3-D3), along with the intrusion factor (B1-B5), which was then called a 'Dysphoria' model. Again, different research studies have supported the presented model (Armour \& Shevlin, 2010; Baschnagel, O'Connor, Colder, \& Hawk, 2005; Boelen, van den Hout, \& van den Bout, 2008; Engdahl, Elhai, Richardson, \& Frueh, 2011; Rademaker et al., 2012) and started another discussion on possible moderators which make one of the models fit better than the other. The research in this area showed that the possible moderators are self-reported vs. interview-based PTSD assessments (Palmieri et al., 2007), referring to the single worst trauma or a long-life trauma history (Elhai et al., 2009) and meeting the A2 criterion or not (Armour et al., 2011). Other four-factor models were presented; however, they were not sufficiently supported empirically and theoretically and thus did not gain the recognition of scientists (Elklit \& Shevlin, 2007; McWilliams, Cox, \& Asmundson, 2005). Shevlin and Elklit (2012) suggested that an accurate model of PTSD symptoms structure should be based on diversely traumatized populations, as different models proved to fit better to victims of car accident trauma resulting in whiplash ('Dysphoria' model) or bereaved patients ('Emotional Numbing' model). Lastly, Elhai et al. (2011) proved that D1-D3 criteria create a unique construct and consequently presented a well-fitted five-factor model of re-experiencing (B1-B5), avoidance (C1-C2), emotional numbing (C3-C7), dysphoric arousal (D1-D3) and anxious arousal (D4-D5). This model, called 'Dysphoric Arousal', has been recently supported by Bennet, Kerig, Chaplo, McGee, and Baucom (2014) in a study on a group of adolescents. 
Bogdan Zawadzki, Agnieszka Popiel, Edna B. Foa, Barbara Jakubowska, Maria Cyniak-Cieciura, Ewa Pragłowska

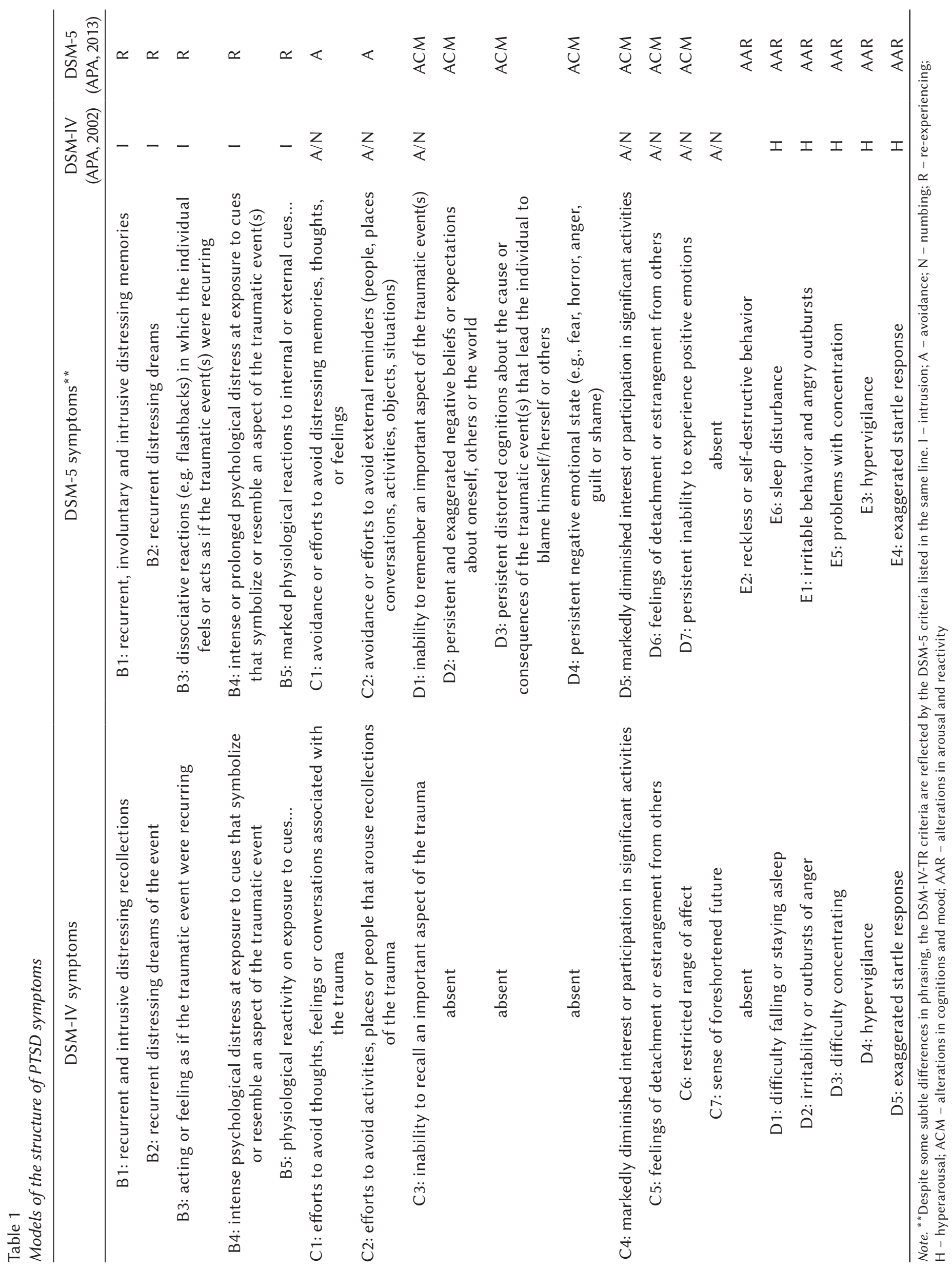


At present, with the publication of the DSM-5 classification (American Psychiatric Association, 2013), and before the release of International Statistical Classification of Diseases and Related Health Problems 11 (ICD-11), the question arises about adequacy of the proposed, new PTSD symptom clusters to accurately present the structure of the disorder, especially in light of the new criterion, which refers to posttraumatic negative cognitions and alterations in mood. Posttraumatic cognitions about the self, the world and self-blame were described and measured by Foa et al. (Foa, Ehlers, Clark, Tolin, \& Orsillo, 1999) and were supported by other research (Startup, Makgekgenene, \& Webster, 2007; Beck et al., 2004). The DSM-5 PTSD definition proposes a model of four symptom clusters: intrusion, avoidance, negative alterations in cognitions and mood, as well as alterations in arousal and reactivity, covering 20 symptoms (compared to 17 symptoms in 3 clusters in the DSM-IV). The differences between DSM-IV and DSM-5 diagnostic criteria are presented in Table 1 and the comparison of models of PTSD symptoms structure based on these two classifications in Table 2. All of them were taken into consideration and tested in our study.

As dysphoria and numbing symptoms are rather non-specific for PTSD diagnosis, some researchers view these new PTSD criteria as too broad and including not only the core PTSD symptoms but also symptoms characteristic for other disorders (mainly mood and anxiety disorders).

In the present study we aimed to examine the structure of symptoms of PTSD as described in DSM-5, in the context of the models most studied to date based on DSM-IV (American Psychiatric Association, 2002), DSM-5 (American Psychiatric Association, 2013), as well as the models developed by King et al. (1998), Simms et al. (2002) and Elhai et al. (2011). Our question was the location of the three symptoms referring to the negative alterations in cognitions and mood (newly added in DSM-5) within this structure.

\section{PARTICIPANTS AND PROCEDURE}

\section{SAMPLE}

The non-clinical sample consisted of 388 recruited participants (who provided written informed consent): 150 males and 239 females (61.30\%) aged 18-83 $(M=34.33, S D=13.21)$, with the most frequent education level being college (39.60\%) and university (56\%). Subjects reported experiencing from 1 to 6 traumatic events $(M=1.83, S D=0.99)$ and as the most traumatic one indicated life-threatening illness ( $n=115,29.60 \%)$, physical assault ( $n=43,11.10 \%)$, sexual assault $(n=16$, $4.10 \%)$, war experience $(n=11,2.80 \%)$, child abuse $(n=38,9.80 \%)$, accident $(n=119,30.70 \%)$, natural disaster $(n=21,5.40 \%)$ and others $(n=25,6.40 \%)$, such as witnessing suicide, dog attack on children, technological disaster, etc. Although the PDS-5 does not contain any item about the time since the trauma, such a question was asked by the investigators. The participants indicated experiencing the index trauma from one month to several years before the study $(M e=36.0$ months $-23.20 \%$ persons within the first year after the trauma, $39.10 \%$ within two years). Data obtained from 24 persons with incomplete answers were removed from the analysis, which was based on a complete data set of 388 individuals.

\section{INSTRUMENTS}

Participants completed the Polish version of the Posttraumatic Diagnostic Scale for DSM-5 (PDS-5) developed by Foa and colleagues (unpublished paper). The original scale was independently translated into Polish by the authors (BZ, AP), backtranslated, and the final version is a result of comparison of all versions and clarification of minor discrepancies ( $\mathrm{Za}-$ wadzki et al., in press). The PDS-5 consists of a list of traumatic events and 20 items assessing symptoms of PTSD, according to the DSM-5 criteria, as well as two items assessing the level of distress experienced by individuals, the level of influence the symptoms have on everyday life, and two items referring to the symptoms onset and duration. Posttraumatic stress disorder symptoms are scored on a 5-point scale indicating how frequently symptoms have been happening and how much they upset the subject during the preceding month $(0=$ not at all, $1=$ once a week or less/ a little, $2=2$ to 3 times a week/somewhat, $3=4$ to 5 times a week/very much and $4=6$ or more times a week/ severe). Posttraumatic Diagnostic Scale for DSM-5 items' means and SDs are presented in Appendix A for raw scores and scores dichotomized into symptoms (answer not at all = lack of the symptom coded as 0 and answers from 1 to 4 points = symptom present coded as 1). Notes to Appendix A also contain information about the frequency of PTSD diagnosis based on the symptoms only and criteria B, C, D, E, $\mathrm{F}, \mathrm{G}$ and $\mathrm{H}$ in the studied sample. Reliabilities of PDS-5 are presented in notes to Table 3.

\section{PROCEDURE}

The study, approved by the Ethical Committee for Psychological Studies, was conducted by the Robert Zajonc Institute for Social Studies at the University of Warsaw in 2014. It was considered as a pilot for PDS-5 and no other instruments were employed. The confirmatory factor analysis was performed by the robust Diagonally Weighted Least Squares (DWLS) method on a polychoric correlation matrix with a matrix of asymptotic covariances by Lisrel 8.72 . 
Bogdan Zawadzki, Agnieszka Popiel, Edna B. Foa, Barbara Jakubowska, Maria Cyniak-Cieciura, Ewa Pragłowska

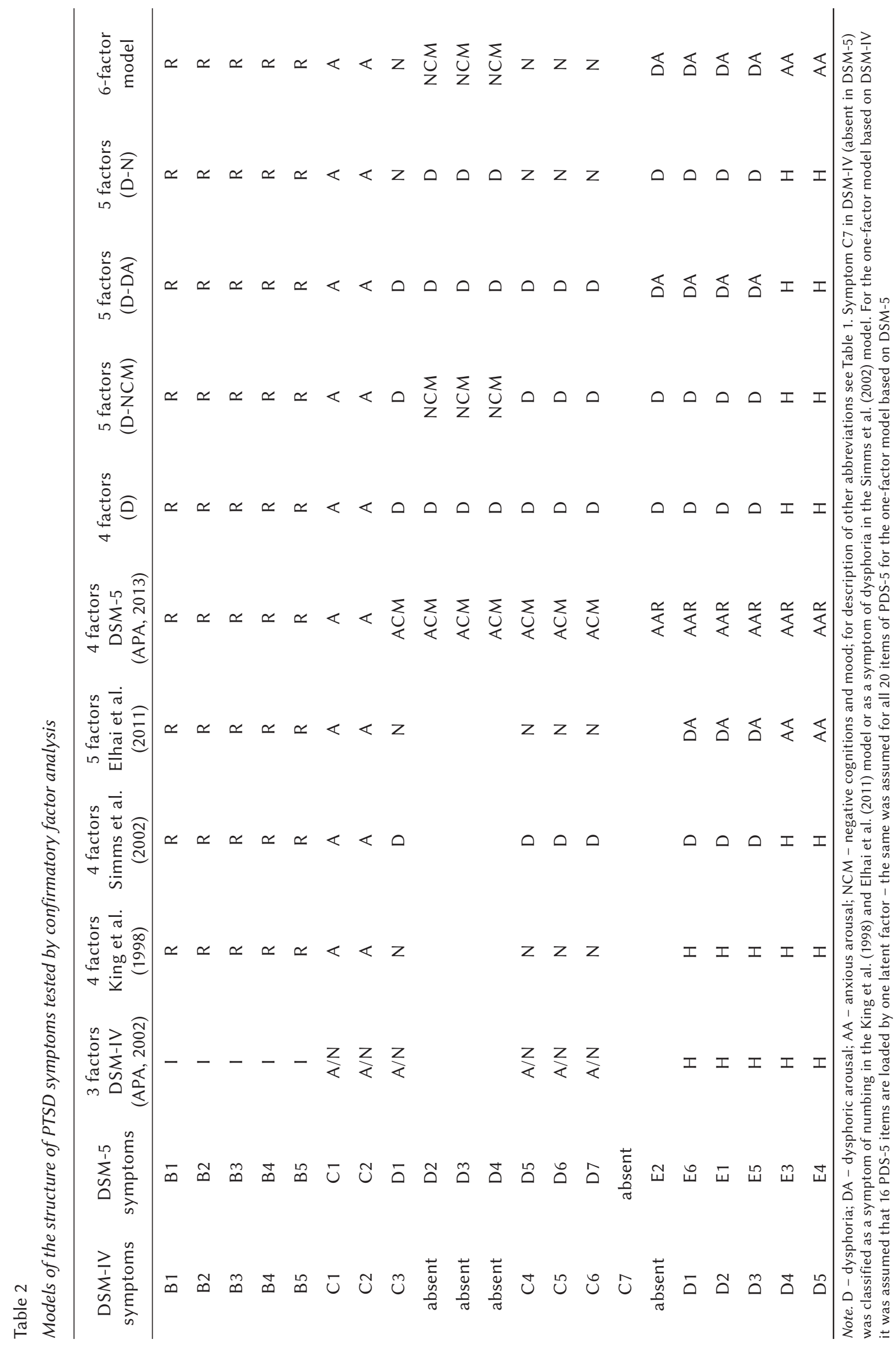


Table 3

Results of confirmatory factor analysis of PDS-5

\begin{tabular}{ccccccccc}
\hline Model & $d f$ & Satorra-Bentler $\chi^{2}$ & RMSEA & GFI & AGFI & CFI & AIC & SRMR \\
\hline One factor (DSM-IV) & 103 & 696.89 & .120 & .988 & .984 & .966 & 762.89 & .070 \\
Three factors (DSM-IV) & 101 & 425.89 & .091 & .992 & .989 & .981 & 495.89 & .061 \\
$\begin{array}{c}\text { Four factors } \\
\text { (King et al., 1998) }\end{array}$ & 98 & 246.59 & .063 & .995 & .993 & .991 & 322.59 & .051 \\
$\quad$ Four factors & & & & & & & & \\
(Simms et al., 2002) & 98 & 230.08 & .059 & .996 & .994 & .992 & 307.08 & .047 \\
$\quad$ Five factors & & & & & & & & \\
$\quad$ Elhai et al., 2011) & 94 & 192.78 & .052 & .996 & .995 & .994 & 276.78 & .045 \\
One factor (DSM-5) & 170 & 1008.06 & .113 & .988 & .986 & .969 & 1088.06 & .071 \\
Four factors (DSM-5) & 167 & 560.60 & .078 & .992 & .990 & .985 & 646.60 & .059 \\
Four factors (D) & 164 & 378.74 & .058 & .995 & .994 & .992 & 470.74 & .050 \\
Five factors (D-NCM) & 160 & 345.96 & .055 & .996 & .994 & .993 & 445.96 & .048 \\
Five factors (D-DA) & 160 & 349.51 & .055 & .996 & .994 & .993 & 449.51 & .048 \\
Five factors (D-N) & 160 & 347.41 & .055 & .996 & .994 & .993 & 447.41 & .049 \\
Six factors & 155 & 310.03 & .051 & .996 & .995 & .994 & 420.03 & .047 \\
\hline
\end{tabular}

Note. For description of models see Table 2; six-factor model refer to Elhai et al., 2011 model of PTSD extended by negative cognitions and mood with symptom D4 included into NCM and E2 into DA. Six-factor model with symptom E2 classified into NCM or into AA as well as symptom D4 classified into DA showed worse fit than the basic six factors model. Cronbach's $\alpha$ for whole PDS-5 scale (20 items) was equal in this study .95 and .91 (for R subscale: 5 items), .83 (A: 2), .91 (ACM: 7 ) and .85 (AAR: 6). Cronbach's $\alpha$ for scales based on six factors model was equal .91 (for R: 5 items), .83 (A: 2), .84 (NCM: 3), .84 (N: 4), .79 (DA: 4 ) \& $.84(\mathrm{AA}: 2)$.

\section{The PDS-5 structure of PTSD according to DSM-IV}

At the beginning, the fit of the five models based on DSM-IV was examined regarding 16 symptoms of PTSD, except three items assessing negative cognitions and mood, and symptom E2 (absent in DSM-IV). They refer to the model of one general factor, three factors, four factors, according to King et al. (1998) and Simms et al. (2002), and five factors (Elhai et al., 2011; see Table 2; models assumed correlation among latent variables, without higher-order factors). The aim of this analysis was to examine the extent to which the items of PDS-5 referring to the PTSD DSM-IV symptoms retained in DSM-5 were able to reach the same structure of symptoms as other instruments (as well as earlier PDS; Foa, Cashman, Jaycox, \& Perry, 1997; see for instance Dragan, Lis-Turlejska, Popiel, Szumiał, \& Dragan, 2012).

\section{The PDS-5 structure of PTSD according to DSM-5}

In the final analysis seven models were tested. The first models were derived from DSM-5 with one general latent factor and four factors: intrusion, avoidance, negative alterations in cognitions and mood, and alterations in arousal and reactivity. This model also refers to the extended model of King et al. (1998).
The next four models refer to the Simms et al. (2002) proposed structure of PTSD symptoms, with the broad dysphoria factor and three additional factors resulting from separating its components: numbing, negative cognitions and mood or dysphoric arousal. The last model was derived from analyses by Elhai et al. (2011) with six factors: re-experiencing, avoidance, numbing, dysphoric arousal, anxious arousal and negative cognitions and mood.

\section{RESULTS}

Results of initial confirmatory factor analyses indicated that the best indices of fit were obtained for the model postulated by Elhai et al. (2011) with five factors: re-experiencing, avoidance, numbing, dysphoric arousal and anxious arousal (see Table 3). The model also showed a better fit than other competitive models, especially four-factor ones $\left(\Delta \chi^{2}>9.49\right.$ for $\Delta d f=4$ and $p=.050$ ), although their fit was also acceptable - except the model with one general factor; see Schermelleh-Engel, Moosbrugger, and Müller (2003).

Similar results were obtained in the analyses of all 20 items of the PDS-5. First, all of the analyzed models - except the model with one general factor 
- showed an acceptable fit (Schermelleh-Engel et al., 2003). Second, the four-factor model referring to the extended Simms et al. (2002) model with the broad dysphoria factor demonstrated a better fit than models based on DSM-5. Third, the five-factor model separating subcomponents of the broad dysphoria factor (DA, NCM or N) showed a better fit than the four-factor model $\left(\Delta \chi^{2}>9.49\right.$ for $\Delta d f=4$ and $\left.p=.050\right)$, which suggests the possibility to split the dysphoria factor into its subdimensions. Finally, the model derived from the Elhai et al. analyses (2011) with reexperiencing, avoidance, anxious arousal, numbing, and dysphoric arousal factors and a new factor, negative cognitions and mood (model nested in four- and five-factor models), showed the best indices of fit and was better than all five-factor $\left(\Delta \chi^{2}>11.07\right.$ for $\Delta d f=5$ and $p=.050)$ and four-factor models $\left(\Delta \chi^{2}>19.92\right.$ for $\Delta d f=9$ and $p=.050)$. These results suggest that symptoms of negative cognitions and mood should be considered as a separate factor in the conceptualization of PTSD in DSM-5 and that the six-factor model accurately characterizes the structure of PTSD symptoms. This model is presented in Figure 1.

Following the idea that (Maercker et al., 2013) the DSM-5 conceptualization of PTSD may cover specific symptoms related only to PTSD, an additional set of hierarchical confirmatory factor analysis was conducted. The highest order PTSD latent factor was extracted (comprising all six latent symptom cate- gories) and compared to the model with two latent factors: broad PTSD factor and specific PTSD symptoms factor (re-experiencing, avoidance and anxious arousal). The model with one PTSD factor showed an acceptable fit (Satorra-Bentler $\chi^{2}=387.35, d f=164$, $p<.001$, RMSEA $=0.06, \mathrm{CFI}=0.99, \mathrm{GFI}=0.99, \mathrm{AGFI}=$ $=0.99, \mathrm{SRMR}=0.06, \mathrm{AIC}=479.35)$, but was worse in comparison to the model separating PTSD core symptoms from broad PTSD $\left(\mathrm{S}-\mathrm{B} \chi^{2}=270.57, d f=160\right.$, $p<.001, \mathrm{RMSEA}=0.04, \mathrm{CFI}=0.99, \mathrm{GFI}=0.99, \mathrm{AGFI}=$ $=0.99, \mathrm{SRMR}=0.05, \mathrm{AIC}=370.57 ; \Delta \chi^{2}=116.78>9.49$ for $\Delta d f=4$ and $p=.050)$. Factor loadings of the general factor were equal to: .61 (R), .55 (A), .96 (DA), .96 $(\mathrm{N}), .99(\mathrm{NCM}), .97(\mathrm{DA})$ and $.72(\mathrm{AA})$ and for core PTSD latent symptoms: .47 (R), .52 (A) and .22 (AA) with the correlation between both factors equal to .48. These data suggest that it is reasonable to separate the core PTSD symptoms (specific only for PTSD) from broad PTSD symptomatology (specific for PTSD as well as for complex PTSD).

\section{DISCUSSION}

The aim of the study was to explore the newly proposed (by DSM-5) latent structure of PTSD symptoms using a self-report measure. Our results suggest that the model that most accurately characterizes the structure of PTSD symptoms described in DSM-5 is

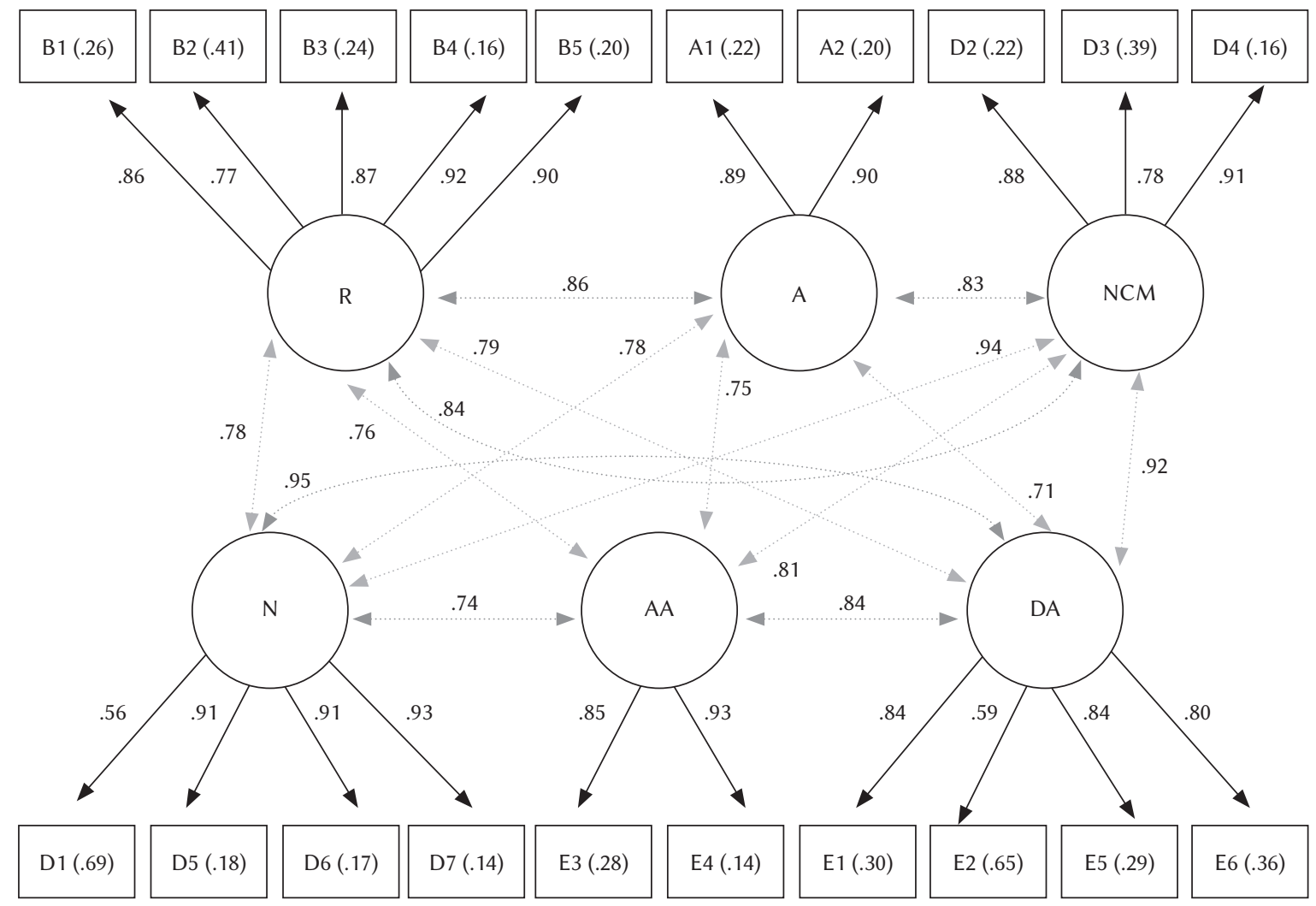

Note. For description of abbreviations see Table 1 and 2. Errors are given in parentheses. All factor loadings and correlations are significant at $p<.05$.

Figure 1. Model of symptoms of PTSD, assessed by PDS-5. 
the six-factor one. The symptoms of negative cognitions and mood should be considered as a separate factor in the conceptualization of PTSD in DSM-5.

The results of our research indicate that while DSM-5's authors took a step towards taking into consideration the empirical findings of King et al. (1998) by creating a separate criterion of avoidance, they have not kept up the momentum. The initial analysis based on symptoms according to DSM-IV proved that the best model contains 5 factors according to the proposal of Elhai et al. (2011). This result is consistent with a previous study that used the PDS by Dragan et al. (2012), who achieved a slightly better fit of the 5-factor model than the classical DSM-IV 3-factor model of PTSD symptoms.

The final analysis of all the 20 symptoms of PTSD listed in DSM-5 revealed that the best fitting model is again the one based on analyses by Elhai et al. (2011) with the additional factor of negative alterations in cognitions and mood. The main difference between the 6-factor model and the DSM-5 model is the categorization of the non-specific symptoms of numbing (D5, D6, D7) and dysphoric arousal (E1, E2, E5, E6) as separate factors.

Our findings correspond with suggestion made by Maercker et al. (2013) in an article concerning proposals for ICD-11 to narrow the list of PTSD symptoms to the core diagnostic features of re-experiencing, avoidance and symptoms of anxious arousal. In the same paper the authors support a new category of complex PTSD, which, as they suggest, could arise "after exposure to a stressor typically of an extreme or prolonged nature and from which escape is difficult or impossible". Symptoms of complex PTSD consist of core PTSD symptoms and additional symptoms of persistent and pervasive impaired affective, self and relational functioning. This idea is weakened by Hetzel-Riggin's and Harbke's analysis of hierarchical structures of PTSD (2014), which showed that the 'Dysphoric Arousal' model provided the best fit, when the symptom categories were only correlated and no higher level factor(s) were introduced into the model. The contradictory results pose a fundamental question of how to conceptualize PTSD: Are there one or two higher level factors which connect lower level factors? Are there core symptoms of PTSD and peripheral non-specific factors? And should these non-specific factors be considered when diagnosing PTSD? The results obtained in the present study suggest the possibility of separating a specific PTSD factor and broad general PTSD factor, but they obviously require independent empirical support.

One of the main limitations of this study is the use of only a self-assessment measure of PTSD. To overcome this shortcoming it would be of great benefit to use both self-report and interview methods. Our analyses were limited by the lack of mood and anxiety disorder symptom measures in the study. It would be beneficial to assess discriminant validity of scales assessing numbing and dysphoric arousal. The study would benefit from a clinical sample of individuals seeking help due to probable PTSD-related symptoms, and (given that a history of trauma may be present in a wide range of mental disorders) in whom the predominance of PTSD in the clinical picture has been confirmed. Nevertheless, we established that questions about the structure of PTSD remain open for further discussion. The proposed new category of alterations in cognitions and mood should be divided into two factors: of numbing (D1, D5, D6, D7) and of negative cognitions and mood (D2, D3, D4). Our study also supports the differentiation between dysphoric (E1, E2, E5, E6) and anxious arousal (E3, E4). Future studies are still needed to determine the proper conceptualization of PTSD.

Study supported by the Grant 2012/06/A/HS6/00340 "PTSD: Diagnosis Therapy Prevention" from Polish National Science Centre.

\section{References}

American Psychiatric Association (1980). Diagnostic and Statistical Manual of Mental Disorders. $3^{\text {rd }}$ ed. Washington, DC: Author.

American Psychiatric Association (2000). Diagnostic and Statistical Manual of Mental Disorders. $4^{\text {th }}$ ed. revised. Washington, DC: Author.

American Psychiatric Association (2013). Diagnostic and Statistical Manual of Mental Disorders. $5^{\text {th }}$ ed. Washington, DC: Author.

Armour, C., \& Shevlin, M. (2010). Testing the dimensionality of PTSD and the specificity of the dysphoria factor. Journal of Loss and Trauma, 15, 11-27.

Armour, C., Layne, C. M., Naifeh, J. A., Shevlin, M., Duraković-Belko, E., Djapo, N., Pynoos R. S., \& Elhai, J. D. (2011). Assessing the factor structure of posttraumatic stress disorder symptoms in participants with and without criterion A2 endorsement. Journal of Anxiety Disorders, 25, 80-87.

Asmundson, G. J. G., Frombach, I., McQuaid, J., Pedrelli, P., Lenox, R., \& Stein, M. B. (2000). Dimensionality of posttraumatic stress symptoms: A confirmatory factor analysis of DSM-IV symptom clusters and other symptom models. Behavior Research and Therapy, 38, 203-214.

Baschnagel, J. S., O'Connor, R. M., Colder, C. R., \& Hawk, L. W. (2005). Factor structure of posttraumatic stress among Western New York undergraduates following the September 11th terrorist attack on the World Trade Center. Journal of Traumatic Stress, 18, 677-684.

Beck, J. G., Coffey, S. F., Palyo, S. A., Gudmundsdottir, B., Miller, L. M., \& Colder, C. R. (2004). Psycho- 
metric properties of the Posttraumatic Cognitions Inventory (PCTI): A replication with motor vehicle accident survivors. Psychological Assessment, 16, 289-298.

Bennet, D. C., Kerig, P. K., Chaplo, S. D., McGee, A. B., \& Baucom, B. R. (2014). Validation of the five-factor model of PTSD symptom structure among delinquent youth. Psychological Trauma: Theory, Research, Practice, and Policy, 6, 438-447.

Boelen, P. A., van den Hout, M. A., \& van den Bout, J. (2008). The factor structure of posttraumatic stress disorder symptoms among bereaved individuals: A confirmatory factor analysis study. Journal of Anxiety Disorders, 22, 1377-1383.

Dragan, M., Lis-Turlejska, M., Popiel, A., Szumiał, S., \& Dragan, W. (2012). The validation of the Polish version of the Posttraumatic Diagnostic Scale and its factor structure. European Journal of Psychotraumatology, 3, 18479. DOI: 10.3402/ejpt.v3i0. 18479.

Elhai, J. D., Biehn, T. L., Armour, C., Klopper, J. J., Frueh, B. C., \& Palmieri, P. A. (2011). Evidence for a unique PTSD construct represented by PTSD's D1-D3 symptoms. Journal of Anxiety Disorders, 25, 340-345.

Elhai, J. D., Engdahl, R. M., Palmieri, P. A., Naifeh, J. A., Schweinle, A., \& Jacobs, G. A. (2009). Assessing posttraumatic stress disorder with or without reference to a single, worst traumatic event: examining differences in factor structure. Psychological Assessment, 21, 629-634.

Elhai, J. D., \& Palmieri, P. A. (2011). The factor structure of posttraumatic stress disorder: A literature update, critique of methodology, and agenda for future research. Journal of Anxiety Disorders, 25, 849-854.

Elhai, J. D., Palmieri, P. A., Biehn, T. L., Frueh, B. C., \& Magruder, K. M. (2010). Posttraumatic stress disorder's frequency and intensity ratings are associated with factor structure differences in military veterans. Psychological Assessment, 22, 723-728.

Elklit, A., \& Shevlin, M. (2007). The structure of PTSD symptoms: A test of alternative models using confirmatory factor analysis. British Journal of Clinical Psychology, 46, 299-313.

Engdahl, R. M., Elhai, J. D., Richardson, J. D., \& Frueh, B. C. (2011). Comparing posttraumatic stress disorder's symptom structure between deployed and non-deployed veterans. Psychological Assessment, 23, 1-6.

Foa, E. B., Cashman, L., Jaycox, L., \& Perry, K. (1997). The validation of a self-report measure of posttraumatic stress disorder: the Posttraumatic Diagnostic Scale. Psychological Assessment, 9, 445-451.

Foa, E. B., Ehlers, A., Clark, D. M., Tolin, D. F., \& Orsillo, S. M. (1999). The Posttraumatic Cognitions Inventory (PTCI): development and validation. Psychological Assessment, 11, 303-314.
Friedman, M. J, \& Karam, E. G. (2009). Posttraumatic stress disorder. In: G. Andrews, D. S. Charney, P. J. Sirovatka, \& D. A. Regier (eds.), Stress induced and fear circuity disorders. Refining the Research Agenda for DSM-V (pp. 3-29). Arlington: APA.

Hetzel-Riggin, M. D., \& Harbke, C. R. (2014, August 4). Hierarchical convergence of PTSD symptom clusters: A comparison of the Numbing, Dysphoria and Dysphoric Arousal models of PTSD. Traumatology. Advance online publication. http://dx.doi. org/10.1037/h0099857.

Kessler, R. C., Berglund, P., Demler, O., Jin, R. \& Walters, E. E. (2005). Lifetime prevalence and age-ofonset distributions of DSM-IV disorders in the National Comorbidity Survey Replication. Archives of General Psychiatry, 62, 593-602.

King, D. W., Leskin, G. A., King, L. A., \& Weathers, F. W. (1998). Confirmatory factor analysis of the Clinician-Administered PTSD Scale: Evidence for the dimensionality of Posttraumatic Stress Disorder. Psychological Assessment, 10, 90-96.

Krause, E. D., Kaltman, S., Goodman, L. A., \& Dutton, M. A. (2007). Longitudinal factor structure of posttraumatic stress symptoms related to intimate partner violence. Psychological Assessment, 19, 165-175.

Maercker, A., Brewin, C. R., Bryant, R. A., Cloitre, M., van Ommeren, M., Jones, L. M., Humayan, A., Kagee, A., Llosa, A. E., Rousseau, C., Somasundaram, D. J., Souza, R., Suzuki, Y., Weissbecker, I., Wessely, S. C., First, M. B., \& Reed, G. M. (2013). Diagnosis and classification of disorders specifically associated with stress: proposals for ICD-11. World Psychiatry, 12, 198-206. [N/A].10.1002/wps.20057.

McWilliams, L. A., Cox, B. J., \& Asmundson, G. J. D. (2005). Symptom structure of posttraumatic stress disorder in a nationally representative sample. Journal of Anxiety Disorders, 19, 626-641.

Palmieri, P. A., Weathers, F., Difede, J., \& King, D. (2007). Confirmatory factor analysis of the PTSD Checklist and the Clinician-Administered PTSD Scale in disaster workers exposed to the World Trade Center ground zero. Journal of Abnormal Psychology, 116, 329-341.

Rademaker, A. R., van Minnen, A., Ebberink, F., van Zuiden, M., Hagenaars, M. A., \& Geuze, E. (2012). Symptom structure of PTSD: support for a hierarchical model separating corer PTSD symptoms from dysphoria. European Journal of Psychotraumatology, 3, 17580. DOI: 10.3402/ejpt.v3i0.17580.

Schermelleh-Engel, K., Moosbrugger, H., \& Müller, H. (2003). Evaluating the fit of structural equation models: Tests of significance and descriptive goodness-of-fir measures. Methods of Psychological Research Online, 8, 23-74.

Shevlin, M., \& Elklit, A. (2012). The latent structure of posttraumatic stress disorder: different models 
or different populations? Journal of Abnormal Psychology, 121, 610-615.

Simms, L. J., Watson, D., \& Doebbelling, B. N. (2002). Confirmatory factor analyses of posttraumatic stress symptoms in deployed and nondeployed veterans of the Gulf War. Journal of Abnormal Psychology, 111, 637-647.

Startup, M., Makgekgenene, L., \& Webster, R. (2007). The role of self-blame for trauma as assessed by the Posttraumatic Cognitions Inventory (PTCl): A self-protective cognition? Behaviour Research and Therapy, 45, 395-403.

Yufik, T., \& Simms, L. J. (2010). A meta-analytic investigation of the structure of posttraumatic stress symptoms. Journal of Abnormal Psychology, 119, 764-776.

Zawadzki, B., Popiel, A., Cyniak-Cieciura, M., Jakubowska, B., \& Pragłowska, E. (2015). Diagnoza pourazowego zaburzenia stresowego (PTSD) za pomocą ustrukturalizowanego wywiadu klinicznego SCID-I [Diagnosis of posttraumatic stress disorder (PTSD) by Structured Clinical Interview SCID-I]. Psychiatria Polska, 49, 159-169. 
Bogdan Zawadzki, Agnieszka Popiel, Edna B. Foa, Barbara Jakubowska, Maria Cyniak-Cieciura, Ewa Pragłowska

\section{Appendix A}

Descriptive statistics of PDS-5 items (raw scores and scores dichotomized into symptoms)

\begin{tabular}{|c|c|c|c|c|}
\hline PDS-5 items & Raw scores $M$ & Raw scores $S D$ & Dichotomized scores $M$ & Dichotomized scores $S D$ \\
\hline B1 & 1.01 & 0.96 & 0.68 & 0.47 \\
\hline B2 & 0.48 & 0.85 & 0.32 & 0.47 \\
\hline B3 & 0.58 & 0.87 & 0.40 & 0.49 \\
\hline B4 & 1.04 & 0.98 & 0.70 & 0.46 \\
\hline B5 & 0.69 & 0.98 & 0.44 & 0.50 \\
\hline $\mathrm{C} 1$ & 0.89 & 1.07 & 0.54 & 0.50 \\
\hline $\mathrm{C} 2$ & 0.80 & 1.10 & 0.46 & 0.50 \\
\hline D1 & 0.55 & 0.92 & 0.36 & 0.48 \\
\hline D2 & 0.79 & 1.18 & 0.41 & 0.49 \\
\hline D3 & 0.67 & 1.06 & 0.39 & 0.49 \\
\hline D4 & 0.95 & 1.11 & 0.57 & 0.50 \\
\hline D5 & 0.66 & 1.07 & 0.36 & 0.48 \\
\hline D6 & 0.69 & 1.13 & 0.36 & 0.48 \\
\hline D7 & 0.72 & 1.08 & 0.41 & 0.49 \\
\hline E1 & 0.68 & 1.01 & 0.41 & 0.49 \\
\hline E2 & 0.38 & 0.82 & 0.24 & 0.43 \\
\hline E3 & 0.97 & 1.13 & 0.55 & 0.50 \\
\hline E4 & 0.88 & 1.17 & 0.47 & 0.50 \\
\hline E5 & 0.90 & 1.15 & 0.50 & 0.50 \\
\hline E6 & 0.74 & 1.07 & 0.42 & 0.49 \\
\hline
\end{tabular}

Note. PTSD according to DSM-5 based on symptoms only (without criterion F) was diagnosed in 161 persons (41.50\%): criterion $\mathrm{B}=78.90 \%$, criterion $\mathrm{C}=59.80 \%$, criterion $\mathrm{D}=59.00 \%$ and criterion $\mathrm{E}=63.70 \%$. Duration of symptoms (criterion $\mathrm{F}$ ): shorter than one month: $23.60 \%$, longer than one month: $76.40 \%$; onset of symptoms (criterion $\mathrm{H}$ ) within six months after trauma: $86.00 \%$, after six months: $14.00 \%$; significant symptom-related distress (criterion G): not at all $=39.20 \%$ (with Me = once a week of less $/$ a little (1 point) on a 5-point scale ranging from (0) not at all to (4) 6 times a week or more/severe or functional impairment (e.g., social, occupational): not at all ( 0 point $)=50.50 \%$. 